\title{
Abnormal arborisations of Purkinje cell dendrites in Creutzfeldt-Jakob disease: a manifestation of neuronal plasticity?
}

\author{
JANICE K TILLER-BORCICH, HENRY URICH \\ From the Department of Pathology (Neuropathology), Stanford University School of Medicine, Stanford, \\ California, USA
}

SUMMARY A case is presented of the ataxic variety of Creutzfeldt-Jakob disease with particular reference to the cerebellar cortex. The main features were loss of granule cells, subtotal in the vermis, severe in the lateral lobes, mild to moderate loss of Purkinje cells and preservation of tangential and basket fibres. The Purkinje cell dendrites showed malorientation and hypertrophy of the primary and secondary branches, the so-called "antler" or "staghorn" deformity. These findings indicate that remodelling of the dendritic tree may start early in the course of the disease even in adults, the total length of history in this case being eight months. They do not throw any additional light on the pathogenesis of the dendritic abnormalities, in particular on the controversy whether they are a non-specific response of the Purkinje cell to a variety of noxious agents or a reaction to partial deafferentation. The authors favour the latter hypothesis.

Bizarre ramifications of Purkinje cell dendrites were described by Nageotte and Léon-Kindberg ${ }^{1}$ and by Cajal. $^{2}$ Neither author provided sufficient data to throw light on the pathogenesis of these abnormalities. Subsequently similar lesions were described in a variety of unrelated conditions, most of them originating in infancy and early childhood. These include primary degeneration of the granular layer, both familial $^{3}$ and sporadic, ${ }^{4}$ Menkes' disease ${ }^{5-7}$ and the "amaurotic idiocies", 8 in particular Batten's disease or ceroid lipofuscinosis. ${ }^{9}$ More recently, similar observations have been made in other conditions, such as cerebello-brain stem leukodystrophy ${ }^{10}$ and ornithine carbamyl transferase deficiency. ${ }^{11}$ In addition, a small group of adult conditions with similar changes has been reported: industrial organic mercury poisoning, ${ }^{12}$ Minamata disease ${ }^{1314}$ and crossed cerebellar atrophy. ${ }^{15} \mathrm{~A}$ common feature of all these conditions is severe rarefaction or subtotal loss of neurons in the granular layer of the cerebellar cortex. The widely held interpretation of the Purkinje cell abnormalities is that they represent a non-specific response to a variety of unrelated factors, genetic, metabolic, toxic or infective. An alternative hypothe-

Address for reprint requests: Janice $\mathrm{K}$ Tiller-Borcich, MD, VA Medical Center, Dept of Pathology, 150 Muir Rd, Martinez, Ca 94553, USA.

Received 23 August 1985. Accepted 16 October 1985 sis ascribes the changes in Purkinje cell dendrites to partial deafferentation. ${ }^{16}$ In the latter case these abnormalities would be an expression of neuronal plasticity which may be defined as an attempt by the neuron to establish new synaptic contacts when its normal connections have either failed to develop (developmental plasticity) or have been destroyed (reactive plasticity).

The main difference between the infantile and the adult cases appears to be in the tempo of evolution of the dendritic abnormalities. They seem to develop rapidly in the former group and may be observed at an early age, while, in the latter, they have been recorded only in cases of extreme chronicity. We have therefore considered it of interest to investigate an adult case with a relatively short clinical history. A case of the ataxic form of Creutzfeldt-Jakob disease appeared to be suitable for this purpose, since atrophy of the granular layer is a feature of this condition $^{17}$ as well as of kuru. ${ }^{18}$

\section{Materials and methods}

The material consisted of the brain of a case of the ataxic form of Creutzfeldt-Jakob disease. ${ }^{19}$ Representative blocks were taken from the cerebral cortex, basal ganglia, thalamus and brain stem, as well as multiple blocks of the cerebellum, both of the vermis and the lateral lobes. All blocks were embedded in paraffin and stained by standard neuro- 


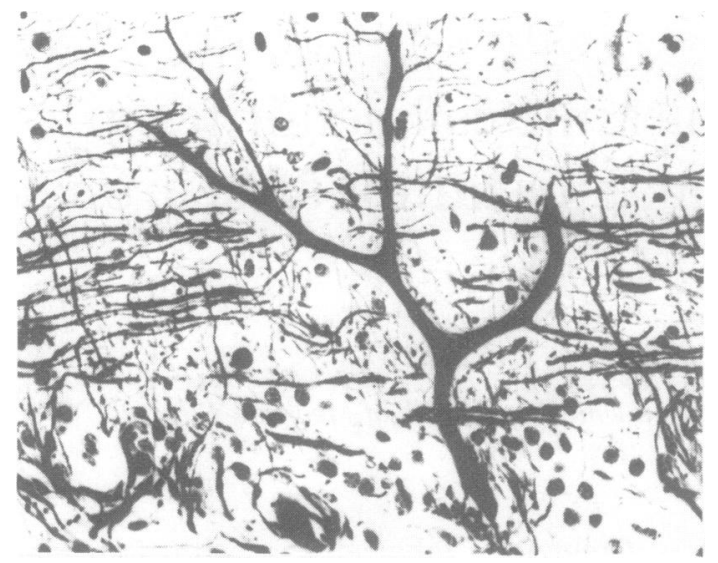

Fig 1 Cerebellar vermis: loss of granule cells, preservation of tangential and basket fibres and "antler" deformity of Purkinje cell dendrite. (Bielschowsky's silver impregnation $\times$ 400.)

pathological techniques, including periodic-acid Schiff (PAS) and a modification of Bielschowsky's silver impregnation. In addition frozen sections of the vermis were stained by Cajal's silvernitrate-pyridine (SNP) method.

\section{Case report}

\section{Clinical history}

A 48-year-old Hispanic male school teacher was in good health until September 1983 when he started complaining of vertigo and diplopia. Subsequently he developed progressive difficulty with balance, fell frequently and had difficulty

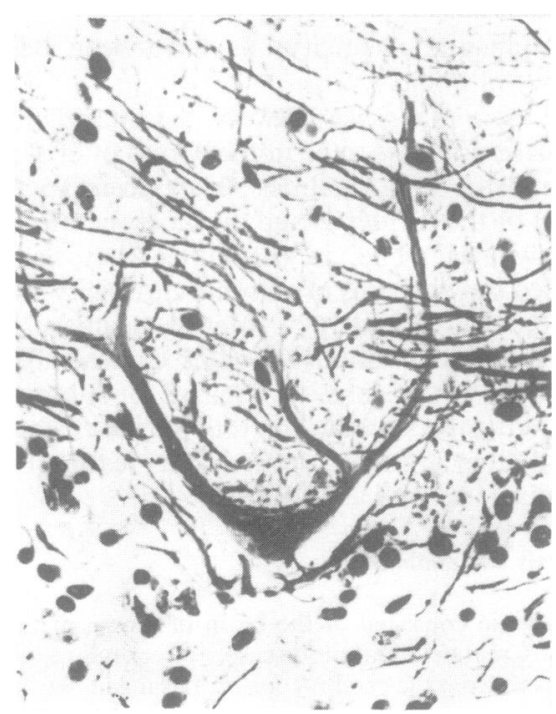

Fig 2 Cerebellar vermis: bidendritic Purkinje cell. (Bielschowsky $\times$ 400.) climbing stairs. On admission to hospital in December 1983 he was fully oriented with some intellectual impairment and short term memory deficits. Other signs included jerky ocular movements, cerebellar dysarthria, broad based gait, truncal ataxia and past pointing, but no myoclonus. CT scan showed atrophy of the cerebellar vermis. The diagnosis of Creutzfeldt-Jakob disease was finally confirmed by brain biopsy. The patient died in May 1984 after a progressive downhill course with increasing dementia.

\section{Pathology}

Cerebral biopsy Fine spongiform changes were seen in the neuropil largely confined to the deeper cortical layers ( $V$ and VI). Electron microscopy showed typical double membrane bound complex vacuoles in the neuropil.

Necropsy revealed no significant general findings. The brain after fixation weighed 1150 grams. Mild cortical atrophy, particularly of frontal and parietal lobes was present with severe cerebellar atrophy with shrunken folia, both in vermis and lateral lobes. Coronal sections revealed flattening of the caudate nucleus and marked atrophy of the putamen. Microscopy The cerebral cortex showed marked spongiform changes in the neuropil, loss of neurons and proliferation of reactive astrocytes, mainly in the deeper layers, in all areas examined. The putamen and caudate nucleus were atrophic, with almost total neuronal loss, intense astrocytic proliferation and coarse status spongiosus. Focal spongiform change, neuronal degeneration and astrogliosis were also present in the thalamus. In the brain stem similar changes were seen in the tectum of the midbrain and basis pontis. In the cerebellum the most striking feature was loss of granule cells, subtotal in the vermis, severe in the lateral lobes, with partial preservation on their inferior surface. The tangential and basket fibres were generally well preserved; some empty baskets were seen in places. Sparse "kuru" plaques were found in the molecular layer. Loss of Purkinje cells was mild to moderate. Many of the surviving Purkinje cells showed abnormalities of their dendrites. Some primary dendrites showed malorientation and were running obliquely or horizontally. Extensive ramification of thick

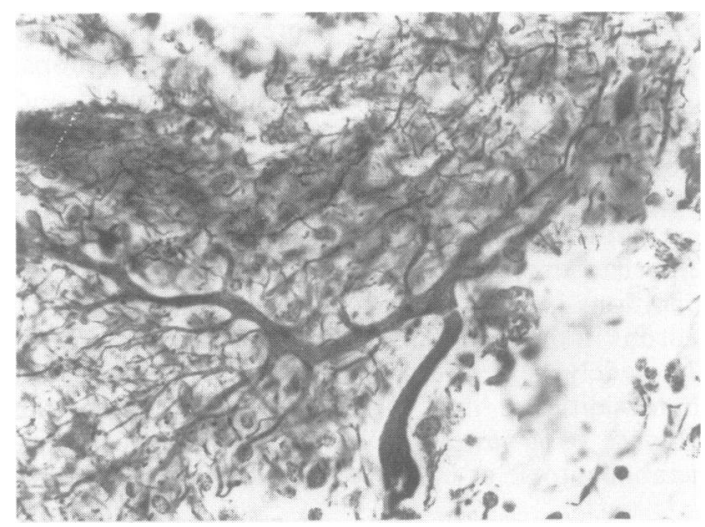

Fig 3 Cerebellar vermis: "antler" deformity of Purkinje cell with abnormal orientation of secondary and tertiary dendritic branches. (Cajal's silver nitrate-pyridine $\times 400$.) 
secondary branches with accentuation of the thickening at bifurcations (the "antler" or "staghorn" pattern) were seen in many cells (fig 1). Several bidendritic cells were present (fig 2). Many secondary branches ran horizontally parallel to the surface, some were directed towards the granular layer in a "weeping-willow" pattern (fig 3). No peripheral spherical expansions ("cactus-like" or "stellate" bodies) and no perisomatic dendrites were seen. The alignment of the Purkinje cells perikarya was normal, no dislocation into the molecular layer being observed. Numerous axonal swellings, both diffuse and fusiform ("torpedoes") were also present. The dentate and roof nuclei were unremarkable.

\section{Discussion}

The abnormalities of the Purkinje cells observed both in the infantile and the adult cases listed above fall into four groups. (1) Aberrant orientation of the primary dendrites which may run horizontally or obliquely. The dendritic tree may cover an abnormally large area, and the primary and secondary dendrites are abnormally thick, particularly at bifurcations. These dendrites show an increased affinity to metallic impregnations and are easily visualised even by methods which do not impregnate normal Purkinje dendrites. Together these changes constitute the "antler" or "staghorn" deformity; the affected cells are frequently bidendritic. (2) Spherical or club shaped peripheral dendritic expansions, with a more deeply staining peripheral rim and a paler centre. These swellings are surrounded by an array of fine radial fibres. They have been recorded under a variety of descriptive terms: "stellate" or "asteroid" bodies, "witches' brooms", "sunray" or "cactus-like" figures. (3) Fine perisomatic dendrites arising radially from the perikaryon of the Purkinje cell. (4) Malorientation and malalignment of the perikarya due to their dislocation into the molecular layer.

Of these abnormalities only the "antler" deformity was seen in the present case and even this was less florid than in some other conditions. Its presence does, however, demonstrate that the process of dendritic remodelling begins early in the course of the disease, even in adults, and is already conspicuous a few months after the onset of symptoms, the total length of history in our case being eight months.

On the other hand the absence of cactus-like or stellate expansions is consistent with the view that they take a long time to develop in adults. Basing his opinion on the experience of Minamata disease, Shiraki ${ }^{14}$ suggested that they are seen only in cases which survived the exposure by at least 15 years; indeed Hunter and Russell's case of industrial mercury poisoning survived for 15 years and the chronic cases of Minamata disease for at least that period after the acute episode. The patient with crossed cerebellar atrophy survived the original insult by 32 years.
These considerations obviously do not apply to children.

Perisomatic dendrites have been studied most extensively in Menkes' disease and have been considered a hallmark of this condition. As they are a normal feature of the foetal Purkinje cell and are shed around the 35th week of gestation, ${ }^{20}$ their apparent persistence has been cited in evidence of the prenatal origin of Purkinje cell abnormalities in this disease. ${ }^{21}$ An alternative explanation is that they may develop de novo after the disappearance of the embryonic perisomatic processes. ${ }^{22}$ Moreover, perisomatic dendrites are not confined to Menkes' disease and have been observed sporadically in other conditions, both infantile and adult. ${ }^{212} 23$ It was Hunter and Russell who first pointed out that this abnormality is found exclusively in Purkinje cells devoid of basket fibres. Loss of basket cells, their axons (tangential fibres) and terminal ramifications (baskets) is a conspicuous feature of Menkes' disease. ${ }^{24} 25$ On the other hand, they are remarkably well preserved in CreutzfeldtJakob disease as they were also in the present case. It is tempting to suggest that persistence or neoformation of perisomatic dendrites is associated with the absence or loss of axosomatic synapses between the basket fibres and the Purkinje cell soma.

Another abnormality associated with the absence of basket fibres is the malalignment of Purkinje cell perikarya due to their dislocation into the molecular layer. This may be tentatively ascribed to loss of tethering of the Purkinje cell by its afferent fibres. ${ }^{1516}$ It was not a feature of the present case.

In conclusion, the observations on this case provide evidence of early remodelling of Purkinje cell dendrites in the direction of the "antler" deformity. The absence of other abnormalities does not contribute to our understanding of their pathogenesis, but does not contradict the current views on their evolution. Our findings do not resolve the controversy between the theories which ascribe the abnormalities of Purkinje dendrites to a direct effect of noxious agents on one hand, and to neuronal plasticity in response to loss of afferents on the other. Excessive, often bizarre, dendritic ramifications in the inferior olive ${ }^{26}$ are associated with lesions in the ipsilateral central tegmental tract or contralateral dentate nucleus. ${ }^{27}$ Similar dendritic abnormalities in the substantia nigra were observed in association with long-standing massive striatal infarction. ${ }^{28}$ The unifying hypothesis which ascribes all these dendritic abnormalities at various sites to a single mechanism, response to partial deafferentation, appears to us far more attractive.

We are grateful to Dr Lysia S Forno for allowing us to use her pathological material. Our thanks are due 
to Ruth Grajeer for technical work, Richard Coffin for the photography and Margaret Beers for secretarial assistance.

\section{References}

${ }^{1}$ Nageotte J, Léon-Kindberg M. Lésions fines du cervelet. (Nodosités des prolongements protoplasmatiques des cellules de Purkinje etc.) Travaux des années 1908-9 du Laboratoire d'Histologie du Collège de France. 1910:50-54.

${ }^{2}$ Cajal S Ramòn. Sur quelques lésions du cervelet dans un case de démence précoce. Travaux du Laboratoire des Recherches Biologiques de l'Université de Madrid. 1926;24:181-90.

${ }^{3}$ Norman RM. Primary degeneration of the granular layer of the cerebellum: an unusual form of familial cerebellar atrophy occurring in early life. Brain 1940;63:365-79.

${ }^{4}$ Ule G. Kleinhirnrindenatrophie vom Körnertyp. Dtsch $Z$ Nervenheilk 1952;168:195-226.

${ }^{5}$ Menkes JH, Alter M, Steigleder GK, Weakley DR, Sung JH. A sex-linked recessive disorder with retardation of growth, peculiar hair and focal cerebral and cerebellar degeneration. Pediatrics 1962;29:764-79.

${ }^{6}$ Aguilar MJ, Chadwick DL, Okuyama K. Kinky hair disease. I. Clinical and pathological features. J Neuropathol Exper Neurol 1966;25:507-22.

${ }^{7}$ Ghatak NR, Hirano A, Poon TP, French JH. Trichopoliodystrophy. II. Pathological changes in skeletal muscle and nervous system. Arch Neurol 1972;26:60-72.

${ }^{8}$ Bielschowsky M. Zur Histopathologie und Pathogenese der amaurotischen Idiotie mit besonderer Berücksichtigung der zerebellaren Veränderungen. $J$ Psychol Neurol 1920;26:123-99.

${ }^{9}$ Norman RM. Malformations of the nervous system, birth injury and diseases of early life. In: Greenfield JG, ed. Neuropathology 1st ed. London: Edward Arnold, 1958:300-407.

${ }^{10}$ Kaga M, Kawasaki M, Mizuno Y, Ohuchi M, Nagashima K, Mohri N. Cerebello-brain stem orthochromatic leukodystrophy with floppiness and bulbar paralysis. Clin Neuropathol 1984;3:178-84.

${ }^{11}$ Kornfeld M, Woodfin BM, Papile L, Davis LE, Bernard LR. Neuropathology of ornithine carbamyl transferase deficiency. Acta Neuropathol 1985;65:261-4.

${ }^{12}$ Hunter D, Russell DS. Focal cerebral and cerebellar atro- phy in the human subject due to organic mercury compounds. J Neurol Neurosurg Psychiatry 1954;17:235-41.

${ }^{13}$ Shiraki H, Takeuchi T. Minamata disease. In: Minckler J, ed. Pathology of the Nervous System. New York: McGraw-Hill, 1971;2:1651-65.

${ }^{14}$ Shiraki H. Neuropathological aspects of organic mercury intoxication including Minamata disease. In: Vinken PB, Bruyn GH, eds. Handbook of Clinical Neurology. Amsterdam-New York: North Holland Publishing Company, 1979;36:83-145.

${ }^{15}$ Strefling AM, Urich H. Crossed cerebellar atrophy: an old problem revisited. Acta Neuropathol 1982;57:197-202.

${ }^{16}$ Urich H. The plasticity of the Purkinje cell. Clin Exper Neurol 1984;20:203-15.

${ }^{17}$ Brownell B, Oppenheimer DR. An ataxic form of subacute presenile polioencephalopathy (Creutzfeldt-Jakob disease). J Neurol Neurosurg Psychiatry 1965;28:350-61.

${ }^{18}$ Klatzo I, Gajdusek DC, Zigas V. Pathology of kuru. Lab Invest 1959;8:799-847.

${ }^{19}$ Gomori AJ, Partnow MJ, Horoupian DS, Hirano A. The ataxic form of Creutzfeldt-Jakob disease. Arch Neurol 1973;29:318-23.

${ }^{20}$ Zecević M, Rakić P. Differentiation of Purkinje cells and their relationship to other components of developing cerebellar cortex in man. $J$ Comp Neurol 1976;167:27-48.

${ }^{21}$ Williams RS, Marshall PC, Lott IT, Caviness VS. The cellular pathology of Menkes' steely hair syndrome. Neurology (Minneap) 1978;28:575-83.

${ }^{22}$ Purpura DP, Hirano A, French JH. Polydendritic Purkinje cells in $x$-chromosome linked copper malabsorption. A Golgi study. Brain Res 1976;117:125-9.

${ }^{23}$ Fujisawa K, Nakamura A. The human Purkinje cells. A Golgi study in pathology. Acta Neuropathol 1982;56:255-64.

${ }^{24}$ Iwata M, Hirano A, French JH. Degeneration of the cerebellar system in $\mathrm{x}$-chromosome linked copper malabsorption. Ann Neurol 1979;5:542-9.

${ }^{25}$ Tan N, Urich H. Menkes' disease and swayback. A comparative study of two copper deficiency syndromes. $J$ Neurol Sci 1983;62:95-113.

${ }^{26}$ Lhermitte J, Trelles JO. L'hypertrophie des olives bulbaires. Encéphale 1933;28:588-600.

${ }^{27}$ Gautier JC, Blackwood W. Enlargement of the inferior olivary nucleus. Brain 1961;84:341-61.

${ }^{28}$ Forno LS. Reaction of the substantia migra to massive basal ganglia infarction. Acta Neuropathol 1983;62:96-102. 